\title{
MIDDLE RULES AND RHUMB-LINE SAILING
}

\author{
Miljenko Petrović \\ Stonska 1A, 10020 Zagreb, Croatia
}

\begin{abstract}
This work tackles the problem of misconception when using sophisticated mathematical tools, nonlinear optimization in this particular case, to solve a navigational problem. Namely, to reach the Great Circle vertex with two rhumb line legs ensuing the optimized distance, an initial rhumb line course equal to the orthodromic course at middle latitude may be used. The initial course is thereupon optimized by the incremental value steps. The optimized distance is achieved if the rhumb line course is altered towards the vertex at the orthodrome-loxodrome intersection point. As determination of this point cannot be formulated in a closed form, an iterative solution is to be applied. The derived transcendental equation forms a basis for an iterative solution of intersection using the Newton-Raphson method. To the contrary, finding solutions to a system of nonlinear equations can mislead a researcher unable to comprehend and grasp the mathematical meanings of the algorithm. The gist of this essay is a novel concept showing an intrinsic property i.e. orthodrome-loxodrome correlation using a well-known formula.
\end{abstract}

Keywords: marine navigation, middle latitude, middle longitude, orthodrome, loxodrome

\section{INTRODUCTION}

The loxodrome is a transcendental curve spiralling between the North Pole and the South Pole. The orthodrome (Great Circle) is the intersection of the sphere with a plane containing the centre of the sphere. An intrinsic property of these two curves can be found by Napier's Rules of Circular Parts that have been widely used in navigation. To find the infinitesimal distance $d D_{O}$ that the vessel must cover in Great Circle sailing for the orthodromic course to change by a small value $d C_{O}$ i.e. for the unit course alteration, the unit distance is defined as:

$$
d D_{O}=-d C_{O} \sec \varphi_{V} \cot \varphi \cos \varphi
$$

where $\varphi$ denotes geographic (geodetic) latitude whilst $\varphi_{V}$ stands for vertex latitude. Since the orthodrome is a curved line whose true direction changes continually (except for the meridian or the equator), a number of points along the Great Circle are selected, and then connected by loxodromes and followed by rhumb line courses. By using the latitude equation of the middle longitude, the orthodrome (Great Circle) is split into an even number of legs with equal longitude difference. For the shortest overall distance of two piecewise rhumb lines, the essay (Han-Fei et al., 1991) inferred that there must exist a turn point along the initial rhumb line course prior to reaching the vertex latitude $\left(\varphi_{V}\right)$. The paper (Petrović, 2014) proved the existence of the turn point at the orthodromeloxodrome intersection point. The initial rhumb line course equals the orthodromic course at the middle latitude. The rule is mnemonic and straightforward for practical navigation. In the paper (Tseng, 2014) the author claimed that there was a misconception in the article (Petrović, 2014), and tried to construct an algorithm of two piecewise rhumb-lines based on the nonlinear optimization technique, but failed to comprehend that the essay (Petrović, 2014) was referring to the methods evaluated by Han-Fei et al. (1991) whereas no alteration to the initial rhumb line course was made, i.e. reaching the vertex latitude or intersecting a great circle in that particular case. The question was to find a turn point along the initial rhumb line course prior to reaching the vertex latitude. It's thereby restricted and equal to the orthodromic course at the middle latitude at which the arc length of the parallel is equal to the departure in proceeding between two points:

$$
C_{O_{\text {Mid }}}=\arcsin \frac{\cos \varphi_{V}}{\cos \varphi_{\text {Mid }}}
$$


Free turning point was not discussed in the paper (Petrović, 2014), which does not mean that the proposed model could not deal with it. As the initial value is important for convergence speed, in lieu of taking a well- known formula for middle longitude the concept of middle latitude was used to obtain the intersection point $(I)$. The initial rhumb line course $\left(\theta_{T}\right)$ is then altered by an incremental value of $\pm 0.1^{\circ}$ (converted into radians) and evaluated as $\theta_{T}^{\prime}$. After few iterative steps (NewtonRaphson method), $\theta_{T}^{\prime}$ reaches the free turning point $I^{\prime}$ on the same great circle, thus determining the optimized distance $\left(D_{T T^{\prime} V}\right)$ (Petrović, 2015). Detailed mathematical explanation will be shown further in the paper, along with comparison with flawed results obtained by Tseng (2014).

\section{ANALYSIS}

\section{FINDING THE ORTHODROME-LOXODROME INTERSECTION ON THE SPHERE}

Taking $C_{O_{\text {Mid }}}$ as an initial rhumb line course $\left(\theta_{T}\right)$ from the point of departure $(T)$ leads to the intersection $(I)$ of a loxodrome with an orthodrome (Great Circle), as shown in Fig. 1. As determination of the orthodrome-loxodrome intersection cannot be formulated in a closed form, an iterative solution is to be derived. The transcendental differentiable function defined on the interval $\left[\lambda_{\mathrm{T}}, \lambda_{\mathrm{V}}\right]$ and expressed by the equation (Petrović, 2014):

$$
f\left(\lambda_{I}\right)=\sinh \left[\cot \theta_{T} \cdot\left(\lambda_{I} \sim \lambda_{0}\right)\right]-\tan \left|\varphi_{V}\right| \cdot \cos \left(\lambda_{V} \sim \lambda_{I}\right)
$$

$\left(\lambda_{0}\right.$ - equatorial intersection longitude of the loxodrome) and its derivatives with respect to $\lambda_{I}$ :

$$
f^{\prime}\left(\lambda_{I}\right)=\cosh \left[\cot \theta_{T} \cdot\left(\lambda_{I} \sim \lambda_{0}\right)\right] \cdot \cot \theta_{T}-\tan \left|\varphi_{V}\right| \cdot \sin \left(\lambda_{V} \sim \lambda_{I}\right)
$$

and

$$
f^{\prime \prime}\left(\lambda_{I}\right)=\sinh \left[\cot \theta_{T} \cdot\left(\lambda_{I} \sim \lambda_{0}\right)\right] \cdot \cot ^{2} \theta_{T}+\tan \left|\varphi_{V}\right| \cdot \cos \left(\lambda_{V} \sim \lambda_{I}\right)
$$

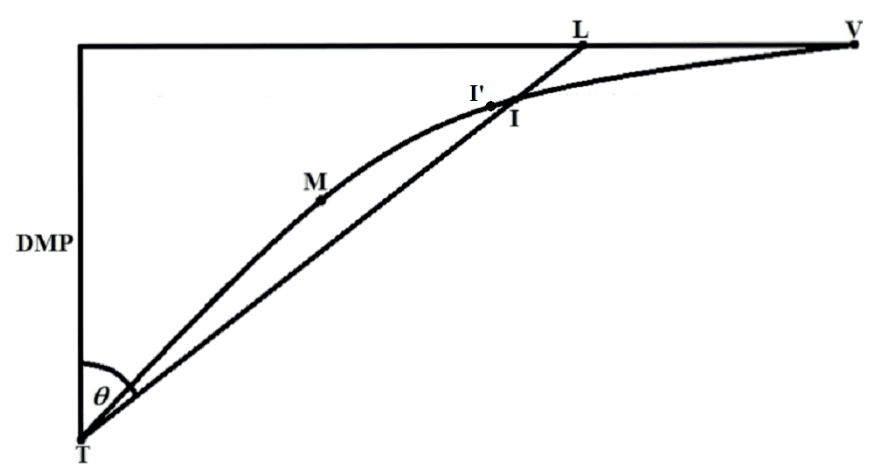

Fig. 1. Middle latitude rule on the Mercator chart

form a basis for iterative solution of intersection using the Newton-Raphson method. If $\varphi_{T}=0 \Rightarrow \lambda_{T}=\lambda_{0}$. In order to use the above formulas for all quadrants, the difference of longitude sign $(\sim)$ represents the shorter arc of the equator between the two meridians. The vertex latitude $\left(\varphi_{V}\right)$ is taken as an absolute value whilst the rhumb line course $\theta_{T}$ equals:

$$
\left(0<\theta_{T}<\frac{\pi}{2}\right)
$$

Thus the zero of $f\left(\lambda_{T}\right)$ crossing is determined. As an initial estimate (guess) for the intersection longitude $\left(\lambda_{T}\right)$, the geographic vertex longitude $\left(\lambda_{V}\right)$ which satisfies the condition: $f\left(\lambda_{v}\right) \cdot f^{\prime \prime}\left(\lambda_{v}\right)>0$, may be used.

$$
\lambda_{I}=\lambda_{V}-\left[f\left(\lambda_{v}\right) / f^{\prime}\left(\lambda_{V}\right)\right]
$$

If $f\left(\lambda_{r}\right)$ obtained using (6) is larger than the allowed error $\left(E=10^{-6}\right), \lambda_{I}$ is taken as the approximation and the iteration process is repeated till the error decreases below $E$. The iterations converge in a few steps. With nowadays computers' capabilities, the procedure is terminated within a fraction of a second.

The above concept may be used on the rotational ellipsoid (spheroid) but the flow of geodesics on the ellipsoid of revolution (spheroid) differs from the geodesic on the sphere and it is not a great ellipse. As the geodesic (line) on the spheroid is defined by the differential equations, finding its vertex longitude and intersection with the loxodrome requires a different mathematical model. The modified formula (2) which gives the geodesic course at middle latitude is:

$$
C_{G_{\text {Mid }}}=\arcsin \frac{\cos \varphi_{V}}{\cos \varphi_{\text {Mid }}\left(1-e^{2} \sin ^{2} \varphi_{V}\right)^{1 / 2}}
$$

\section{MIDDLE LONGITUDE RULE ON A SPHERE}

In a right angled spherical triangle PTV (Fig. 2.) the longitude difference $(\Delta \lambda)$ can be divided into an even number of equal parts, i.e. $\Delta \lambda / 2$ (named the middle longitude), $\Delta \lambda / 4$, etc. By applying the four-part equation of the spherical trigonometry, the latitude equation of the middle longitude for the geodesic (Great Circle) on the spherical surface is derived as follows (Petrović, 1990]):

$$
\begin{gathered}
\operatorname{ctg}\left(180^{\circ}-\alpha\right) \sin \frac{\Delta \lambda}{2}=g \varphi_{T} \cos \varphi_{m}-\sin \varphi_{m} \cos \frac{\Delta \lambda}{2} \\
\operatorname{ctg} \alpha \sin \frac{\Delta \lambda}{2}=g \varphi_{V} \cos \varphi_{m}-\sin \varphi_{m} \cos \frac{\Delta \lambda}{2}
\end{gathered}
$$




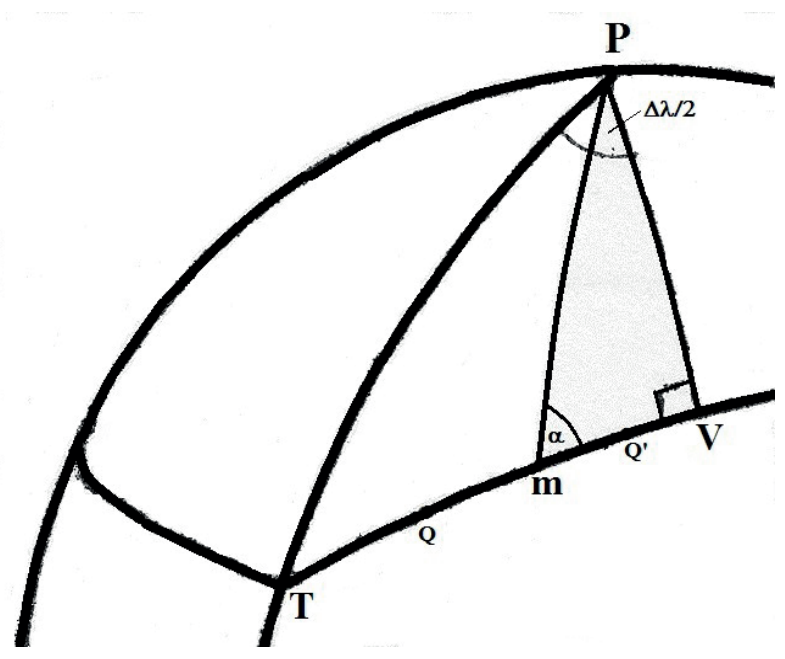

Fig. 2. Middle longitude rule on a sphere

Adding these two equations and rearranging yields:

$$
\operatorname{tg} \varphi_{m}=\frac{\operatorname{tg} \varphi_{T}+\operatorname{tg} \varphi_{V}}{2 \cos \frac{\Delta \lambda}{2}}
$$

The final formula (10) shows that the sum of the tangents of two latitudes divided by the double cosine of middle longitude is equal to the tangent of latitude at middle longitude. By connecting departure $(T)$ and vertex $(V)$ with loxodromes intersecting at the middle longitude $(\mathrm{m})$ point, the two-step distance $(\operatorname{Tm} V)$ is easily deduced. If the longitude difference $\Delta \lambda / 4$ is used, symmetric equations are derived for positions $Q$ and $Q^{\prime}$ :

$$
\begin{aligned}
\operatorname{tg} \varphi_{Q}= & \frac{\operatorname{tg} \varphi_{T}+\operatorname{tg} \varphi_{m}}{2 \cos \frac{\Delta \lambda}{4}}, \\
\operatorname{tg} \varphi_{Q^{\prime}} & =\frac{\operatorname{tg} \varphi_{V}+\operatorname{tg} \varphi_{m}}{2 \cos \frac{\Delta \lambda}{4}} .
\end{aligned}
$$

\section{COMPUTATION ALGORITHM FOR OPTIMIZED DISTANCE}

In the examples presented in Table 1, Greenwich meridian is taken as the departure longitude $\left(\lambda_{T}=0\right)$, whilst $\theta_{I}$ represents the rhumb line course connecting the intersection point $(I)$ with the vertex $(V)$. The distance $\left(D_{T L V}\right)$ is based on rhumb-line $\left(\theta_{T}\right)$ sailing to the vertex latitude then due east (or west) along the parallel to the vertex (Han-Fei et al., 1991). A shorter distance $\left(D_{T I V}\right)$ is obtained if the course is altered to the rhumb line $\left(\theta_{I}\right)$ at $I$, then proceeding towards the vertex (Petrović, 2014).

The free turning point $\left(I^{\prime}\right)$ along the Great Circle ensuing the optimized distance can be reached using the longitude of $I$ or $m$ as an initial value in formula (3). For optimization purposes, the initial rhumb line course $\left(\theta_{T}\right)$ is then altered by an incremental value of $\pm 0.1^{\circ}$ (converted into radians) and inserted into formula (3) as $\theta_{T}^{\prime}$. After few iterative steps (Newton-Raphson method), $\theta_{T}^{\prime}$ reaches the free turning point $I^{\prime}$ on the same Great Circle (Fig. 1.). The optimized distance is obtained if the course is altered to the rhumb line $\left(\theta_{I^{\prime}}\right)$ at $I^{\prime}$, then proceeding towards the vertex as shown in Table 2. The Great Circle Distance $\left(D_{G C}\right)$ serves as a reference value.

Whilst comparing the results, it can be noted that the two-step rhumb-line distance $\left(D_{T m V}\right)$ in (Table 1.) obtained based on the middle longitude method is very close to the optimized distance $\left(D_{T I^{\prime} V}\right)$ (Table 2.).

Tab. 1. Middle latitude vs. middle longitude (Sphere)

\begin{tabular}{|c|c|c|c|c|c|}
\hline$\varphi_{T} / \varphi_{V}$ & $\lambda_{0} / \lambda_{V}$ & $\varphi_{I} / \lambda_{I}$ & $\theta_{T} / \theta_{I}$ & $D_{T L V} / D_{T V}$ & $D_{T m V}$ \\
\hline $5^{\circ} / 25^{\circ}$ & $-14^{\circ} 17.6^{\prime} / 79^{\circ} 11.2^{\prime}$ & $22^{\circ} 25.3^{\prime} / 51^{\circ} 25.1^{\prime}$ & $70.7^{\circ} / 84.2^{\circ}$ & $4702.7^{\prime} / 4695.1^{\prime}$ & $4695.0^{\prime}$ \\
\hline $15^{\circ} / 35^{\circ}$ & $-33^{\circ} 24.8^{\prime} / 67^{\circ} 30.0^{\prime}$ & $32^{\circ} 11.2^{\prime} / 41^{\circ} 30.7^{\prime}$ & $65.6^{\circ} / 82.6^{\circ}$ & $3813.8^{\prime} / 3803.4^{\prime}$ & $3802.7^{\prime}$ \\
\hline $25^{\circ} / 45^{\circ}$ & $-46^{\circ} 02.0^{\prime} / 62^{\circ} 12.3^{\prime}$ & $42^{\circ} 05.5^{\prime} / 36^{\circ} 48.0^{\prime}$ & $60.7^{\circ} / 81.0^{\circ}$ & $3226.4^{\prime} / 3213.7^{\prime}$ & $3212.6^{\prime}$ \\
\hline $35^{\circ} / 55^{\circ}$ & $-54^{\circ} 22.5^{\prime} / 60^{\circ} 38.4^{\prime}$ & $52^{\circ} 03.9^{\prime} / 34^{\circ} 34.8^{\prime}$ & $55.5^{\circ} / 79.3^{\circ}$ & $2767.0^{\prime} / 2752.1^{\prime}$ & $2750.8^{\prime}$ \\
\hline $45^{\circ} / 65^{\circ}$ & $-58^{\circ} 28.0^{\prime} / 62^{\circ} 12.3^{\prime}$ & $62^{\circ} 05.6^{\prime} / 33^{\circ} 54.3^{\prime}$ & $49.2^{\circ} / 77.0^{\circ}$ & $2361.7^{\prime} / 2344.6^{\prime}$ & $2343.5^{\prime}$ \\
\hline
\end{tabular}

Tab. 2. Distance optimized with the middle latitude rule (Sphere)

\begin{tabular}{|c|c|c|c|c|c|}
\hline$\varphi_{T} / \varphi_{V}$ & $\lambda_{0} / \lambda_{V}$ & $\varphi_{I^{\prime}} / \lambda_{I^{\prime}}$ & $\theta_{T}^{\prime} / \theta_{I^{\prime}}$ & $D_{T I^{\prime} V}$ & $D_{G C}$ \\
\hline $5^{\circ} / 25^{\circ}$ & $-13^{\circ} 36.4^{\prime} / 79^{\circ} 11.2^{\prime}$ & $21^{\circ} 08.2^{\prime} / 45^{\circ} 11.4^{\prime}$ & $69.8^{\circ} / 83.0^{\circ}$ & $4694.39^{\prime}$ & $4685.9^{\prime}$ \\
\hline $15^{\circ} / 35^{\circ}$ & $-31^{\circ} 40.3^{\prime} / 67^{\circ} 30.0^{\prime}$ & $30^{\circ} 52.4^{\prime} / 36^{\circ} 08.0^{\prime}$ & $64.4^{\circ} / 81.1^{\circ}$ & $3802.48^{\prime}$ & $3790.6^{\prime}$ \\
\hline $25^{\circ} / 45^{\circ}$ & $-43^{\circ} 30.5^{\prime} / 62^{\circ} 12.3^{\prime}$ & $40^{\circ} 48.0^{\prime} / 31^{\circ} 52.7^{\prime}$ & $59.3^{\circ} / 79.3^{\circ}$ & $3212.54^{\prime}$ & $3197.8^{\prime}$ \\
\hline $35^{\circ} / 55^{\circ}$ & $-51^{\circ} 17.7^{\prime} / 60^{\circ} 38.4^{\prime}$ & $50^{\circ} 50.1^{\prime} / 29^{\circ} 54.9^{\prime}$ & $53.9^{\circ} / 77.3^{\circ}$ & $2750.82^{\prime}$ & $2733.4^{\prime}$ \\
\hline $45^{\circ} / 65^{\circ}$ & $-55^{\circ} 06.6^{\prime} / 62^{\circ} 12.3^{\prime}$ & $60^{\circ} 59.0^{\prime} / 29^{\circ} 24.8^{\prime}$ & $47.5^{\circ} / 74.9^{\circ}$ & $2343.34^{\prime}$ & $2323.2^{\prime}$ \\
\hline
\end{tabular}

\section{COMPARING RESULTS OBTAINED BY PETROVIĆ AND TSENG}

An abstract of relevant results obtained by Tseng (2014), based on the nonlinear optimization technique is shown in Table 3. To make comparison easier, Tseng's symbols for $\varphi_{x}$ and $\lambda_{x}$ are shown as $\varphi_{I}$, and $\lambda_{I}$, in this paper. For each and every value shown as $\lambda_{x}$ in Table 3 , Tseng (2014) got results for $\varphi_{x}$ which do not match the well-known formula:

$$
\varphi_{x}=\arctan \left(\cos \Delta \lambda_{Y} \tan \varphi_{V}\right.
$$

where $\Delta \lambda_{\mathrm{K}}=\lambda_{V}-\lambda_{\mathrm{r}}$. The values in the last column in Table 3 are obtained using the above formula (13) i.e. $\varphi_{x}$ must be on the great circle passing through point $\mathrm{T}$ and having the vertex at V. It's obvious that Tseng's results do not match the required parameters i.e. the nonlinear optimization technique was not properly applied.

Tab. 3. Comparing values by Tseng (2014. - Tab. 2.) with correct values for $\varphi x$

\begin{tabular}{|c|c|c|c|c|c|}
\hline$\varphi_{T} / \varphi_{V}$ & $\lambda_{V}$ & $\lambda_{x}$ & $\varphi_{x}$ & $\Delta \lambda_{V x}$ & $\varphi_{x}$ [correct value] \\
\hline $5^{\circ} / 25^{\circ}$ & $79^{\circ} 11.16^{\prime}$ & $45^{\circ} 33.77^{\prime}$ & $21^{\circ} 1.98^{\prime}$ & $33^{\circ} 37^{\prime} 24^{\prime \prime}$ & $21^{\circ} 13^{\prime} 15^{\prime \prime}$ \\
\hline $15^{\circ} / 35^{\circ}$ & $67^{\circ} 30.05^{\prime}$ & $36^{\circ} 17.86^{\prime}$ & $30^{\circ} 47.78^{\prime}$ & $31^{\circ} 12^{\prime} 11^{\prime \prime}$ & $30^{\circ} 55^{\prime} 05^{\prime \prime}$ \\
\hline $25^{\circ} / 45^{\circ}$ & $62^{\circ} 12.31^{\prime}$ & $31^{\circ} 58.23^{\prime}$ & $40^{\circ} 44.62^{\prime}$ & $30^{\circ} 14^{\prime} 05^{\prime \prime}$ & $40^{\circ} 49^{\prime} 34^{\prime \prime}$ \\
\hline $35^{\circ} / 55^{\circ}$ & $60^{\circ} 38.42^{\prime}$ & $29^{\circ} 57.09^{\prime}$ & $50^{\circ} 47.61^{\prime}$ & $30^{\circ} 41^{\prime} 20^{\prime \prime}$ & $50^{\circ} 50^{\prime} 46^{\prime \prime}$ \\
\hline $45^{\circ} / 65^{\circ}$ & $62^{\circ} 12.31^{\prime}$ & $29^{\circ} 22.83^{\prime}$ & $60^{\circ} 57.07^{\prime}$ & $32^{\circ} 49^{\prime} 29^{\prime \prime}$ & $60^{\circ} 58^{\prime} 25^{\prime \prime}$ \\
\hline
\end{tabular}




\section{CONCLUSIONS}

To reach the Great Circle vertex with two rhumb-line legs ensuing the optimized distance, the initial rhumb line course $\left(\theta_{T}\right)$ equal to the orthodromic course at the middle latitude may be used. Alternatively, the middle longitude $(m)$ point at the same Great Circle can give the initial rhumb line course $\left(\theta_{T}\right)$ as well. The initial course is thereupon optimized by the incremental value steps. The method finds the free turn point ( I') from where a rhumb line course $\left(\theta_{I}\right)$ is followed towards the vertex, which gives an optimized overall distance $\left(D_{T I^{\prime} V}\right)$. Moreover, the results show that distance saving obtained as a result of optimization is not substantial i.e. the middle latitude $\left(D_{T I V}\right)$ and middle longitude $\left(\mathrm{D}_{T m V}\right)$ rules hold good for practical marine navigation. To the contrary, finding solutions to a system of nonlinear equations can mislead a researcher unable to comprehend and grasp the mathematical meanings of the algorithm ensuing in flawed and inconsistent results. The gist of this essay is a novel concept showing an intrinsic property i.e. the orthodrome-loxodrome correlation using a well-known formula (2).

\section{REFERENCES}

1. Bowditch N.: The American Practical Navigator. Bicentennial Edition, National Imagery and Mapping Agency (NIMA), Bethesda, Maryland 2002.

2. Clough-Smith J. H.: An Introduction to Spherical Trigonometry. Brown, Son \& Ferguson, Ltd., Glasgow 1978.

3. Greenberg M.: Advanced Engineering Mathematics. Prentice-Hall Int., New Jersey 1998.

4. Han-Fei Lu, Hsin-Hsiung Fang and Chung-Hsiung Chiang: Trans-oceanic Passages by Rhumbline Sailing. The Journal of Navigation, London-Cambridge, U.K. 1991, Vol. 44, pp.423-428.

5. Kurtz M.: Handbook of Applied Mathematics for Engineers and Scientists. McGraw-Hill Inc., New York 1991.

6. Petrović M.: A note on mid rules optimization of distance on the sphere. Scientific Journal of Maritime Research, Rijeka, Croatia 2015, Vol. 29, pp. 122-124.

7. Petrović M.: Orthodrome-Loxodrome Correlation by the Middle Latitude Rule. The Journal of Navigation, London-Cambridge, U.K. 2014, Vol. 67, pp. 539-543.

8. Petrović M.: Orthodrome. Graduation thesis at the College of Maritime Studies, Dubrovnik, Croatia 1990.

9. Smart W.M.: Textbook on Spherical Astronomy. Cambridge University Press, London 1986.

10. Tseng W.K.: The Shortest Overall Distance of Two Piecewise Rhumb-lines. $10^{\text {th }}$ International Conference on Natural Computation (ICNC), Xiamen-China 2014, pp. 1153-1157.

\title{
CONTACT WITH THE AUTHOR
}

\author{
Miljenko Petrović \\ e-mail:miljenko.petrovic@zg.t-com.hr \\ Stonska 1A, 10020 Zagreb
}

Croatia 